\title{
1. LA LEY SingulAR Y EL PROBLEMA DEL CONTROL DE SU SOPORTE CAUSAL
}

\author{
ANTONIO J. PORRAS NADALES \\ Catedrático de Derecho Constitucional \\ Universidad de Sevilla
}



Revista de Derecho Político, núm. 30, 1989, pp. 9-21

\title{
1. LA LEY SINGULAR Y EL PROBLEMA DEL CONTROL DE SU SOPORTE CAUSAL
}

(A propósito de la STC 163/1986 de 17 de diciembre)

\author{
POR \\ ANTONIO J. PORRAS NADALES \\ Catedrático de Derecho Constitucional \\ Universidad de Sevilla
}

1. La publicación de la STC $166 / 1986$ de 19 de diciembre que resuelve la cuestión de inconstitucionalidad contra la Ley $7 / 1983$ de 29 de junio, resultado de la conversión del Decreto-Ley 2/1983 de 23 de febrero, de expropiación del grupo Rumasa, ha supuesto una reactualización, en el marco de nuestro ordenamiento, del debate en la doctrina y la jurisprudencia europeas sobre el concepto de ley singular, considerada como un supuesto específico de la ley intervencionista (Massnahmegesetz, leggiprovvedimento) caracteristica del Estado social de derecho.

Un debate que obliga ciertamente a retomar, al menos de pasada y desde la perspectiva de su inevitable reactualización histórica, uno de los puntos culminantes en la evolución de la doctrina del derecho público occidental: el discurso sobre el concepto de ley material en cuanto proposición jurídica o regla de derecho (LABAND, JELLINEK), caracterizada por su carácter general o abstracto (THOMA) que debe implicar su adecuación al mecanismo básico de concreción del pacto relacional entre sociedad y Estado -el principio rousseauniano de igualdad-a la hora de establecer limitaciones en la esfera propia de la sociedad civil, la libertad y la propiedad (ANSCHÜTZ, THOMA, FORTSTHOFF).

Se han clarificado suficientemente los peculiares condicionamientos histórico-institucionales que presidieron esta construccion, característica de la monarquía constitucional, en cuanto mecanismo de garantía de la 
sociedad frente al Estado-Monarca (JESCH) destinado a evitar el ejercicio arbitrario del poder. El propio desarrollo posterior del concepto de ley en sentido formal, paralelo al proceso de consolidación del parlamentarismo europeo, opera como un mecanismo de superación/ocultación de los problemas implícitos en las primeras formulaciones. Sobre todo en la medida en que aquéllas permitían expresar, por encima de las peculiares y concretas coordenadas histórico-institucionales, una exigencia funcional característica del universo liberal: la limitación básica de toda actividad intervencionista del Estado sobre la sociedad civil (HABERMAS, OFFE).

La superación del enfrentamiento estructural entre monarca y parlamento, en cuanto proyección del conflicto entre Estado y Sociedad, permite una absolutización del concepto «forma de ley» en el que, sin embargo, se van a dar por supuestos los elementos materiales de generalidad y abstracción característicos de la proposición jurídica, sobre todo en la medida en que tiene que aceptarse, como afirmaría el propio KELSEN, que no caben proposiciones jurídicas fuera de la forma de ley.

De este modo el advenimiento del Estado Social intervencionista no va a suponer formalmente quiebra alguna en el edificio del Estado de Derecho, transformándose el principio de reserva legal básicamente en un mecanismo de habilitación para actos de intervención del Ejecutivo (JESCH), lo que permitirá implementar considerablemente tanto la necesaria flexibilización de las políticas prestadoras, en el ámbito propio del Poder Ejecutivo, como los mecanismos tuteladores de la esfera de garantia de los particulares frente al Estado.

2. Esta visión jurídico-formal provoca, sin embargo, un relativo ocultamiento de las específicas y profundas transformaciones que el fenómeno intervencionista va a producir en el edificio del Estado de Derecho contemporáneo.

En efecto, entender los procesos de creación del derecho intervencionista del Estado actual exclusivamente desde una perspectiva causal formal-vertical, a partir de un omnisoporte legal habilitante, que se explica jerárquicamente en cuanto mero desarrollo (ejecutivo) de los mandatos constitucionales, legitimándose en el vago ideal de la iustitia distributiva, implica desconocer los profundos fenómenos contemporáneos de penetración democrática de la sociedad sobre el Estado, la necesidad de un derecho responsive to social need ${ }^{1}$ capaz de expresar la progre-

1 P. NONET, P. SELZNICK: Law an Society in Transition. Nueva York 1978, Colophon B. págs. 76-77. V. también G. TEUBNER: «Substantive and Reflexive Elements in Modern Law», Law and Society, 1983, 17, págs. 239-285. Tony Prosser: “Towards a Critical Public Law», J. of Law and Society, 1982, 9, págs. 1-19. T. Proser: «Democratisation, Accountability and Institutional Design: Reflections on Public Law», en P. MACAusLan \& J. F. McELdowner: Law, Legitimacy and the Constitucion. Londres, Sweet \& Maxwell, 1985, 170-191. 
siva socialización de los instrumentos jurídicos del Estado intervencionista ${ }^{2}$.

Una alternativa correcta sólo puede basarse en la constatación de la progresiva interconexión funcional entre Sociedad y Estado, lo que, traducido al proceso de creación normativa de los poderes públicos, implica en primer lugar un reforzamiento y creciente incidencia sobre el ámbito material de la norma, de los elementos o condicionamientos fácticos, deducidos de la misma realidad social, que constituyen el soporte material de la respuesta intervencionista del Estado, en vía normativa. Es decir, una mayor interconexión instrumental o causal entre la norma y los condicionamientos o exigencias materiales que están en su base.

En segundo lugar, la necesidad de una mayor aproximación entre la actividad normativa intervencionista y la realidad social afectada por la ley, determina una consecuente reducción selectiva de su ámbito de proyección social: el concepto de ley sectorial se aparecería así como una figura normal y típica, caracterizada por un espacio de incidencia social limitado. Lo cual nos permitiría ciertamente superar el falso dilema ley general-ley singular, para entrar en una variable escala de gradualización del ámbito de proyección social de la norma.

Naturalmente que es posible entender estos cámbios como un fenómeno restringido a la esfera normativa del Ejecutivo ${ }^{3}$, dentro siempre de un marco de habilitación legal ajustado a la tradicional dogmática ${ }^{4}$. Esta posición limitativa produciria un obstáculo insalvable a la actuación intervencionista del Estado en ámbitos sociales tutelados por la órbita dogmática de la Constitución, privando al Poder Legislativo de su capacidad de incidencia sobre el sistema social, al menos hasta el límite nuclear del contenido esencial de los derechos.

3. Por ello la peculiar naturaleza del derecho intervencionista del Estado ha sido entendida en la doctrina como el resultado de una proyec-

2 Como señala L. PALADIN «É l'affermazione della socialità dello Stato che determina... un naturale e profondo mutamento della funzione spettante alla legge», en «La legge come norma e como provvedimentow, Giurisprudenza Costituzionale, 1969, pág. 885. Una posición exclusivamente formalista como la de Dietrich JESCH (Ley y Administración. Estudio de la evolución del principio de legalidad. Madrid 1978. Instituto de Estudios Administrativos) puede llevar hasta afirmaciones tan peregrinas como la de que la estructura constitucional del Estado contemporáneo se caracterizaría por un «debilitamiento del Ejecutivo (al que) coresponde un fortalecimiento del Parlamento" (pág. 220): auténtica visión cubista de la realidad contemporánea estatal que vendria a echar por tierra los frenéticos intentos de alguna reciente doctrina por «reinventar» el Parlamento.

3 Una línea seguida en términos generales por cierta doctrina alemana, como ForsT. HOFF, o MENGER: «Massnahmegesetze seien also nur im Bereich gestaltender Regierung und Verwaltung zulássig", v. CH. STARCK: Der Gesetzesbegriff des Grundgesetzes. Baden-Baden 1970, Nomos, pág. 51.

4 V. Dietrich JESCH, op. cit., segunda parte. 
ción creciente de la función ejecutiva sobre la tradicional esfera formal de la ley, y no a la inversa.

De ahí la referencia de MORTATI en 1968 a la sustancial homogeneidad entre Gobierno y Parlamento a la hora de analizar el fenómeno de las leggi provvedimento ${ }^{5}$, lo que en la característica optica italiana da lugar a su comprensión en el marco de la generalización del concepto de indirizzo politico ${ }^{\circ}$. Una expresión, en definitiva, que traduce la posición activa del Estado Social para la regulación del sistema económico en su conjunto ${ }^{7}$.

Esta relativa asunción de «carácter» reglamentario por la norma legal se traduce, pues, en una mayor interconexión instrumental con sus soportes fácticos causales, así como en una progresiva limitación selectiva de su ámbito social de acción. No deja de resultar en este punto paradigmática la experiencia española de la Ley-Rumasa, que se presenta originariamente como un Decreto-Ley, demostrando así su esencial naturaleza ejecutiva propia de la estrategia de actuación coyuntural de la intervención del Estado en la economía ${ }^{8}$. MORTATI se refiere a este respecto a la dificultad para determinar la naturaleza de la leggi provvedlmento por la via de la separación de la figura del Reglamento ${ }^{9}$, en la medida en que la asunción de ejecutoriedad por la ley se concibe como una lógica consecuencia de la proyección intervencionista del Estado, un fenómeno que coincidiría con la progresiva ampliación del marco de libertad reglamentaria ${ }^{10}$.

Ello no implica ciertamente la imposibilidad de determinar los rasgos distintivos que deben configurar su forma legal: la proyección de una esfera de eficacia exterior erga omnes ${ }^{11}$ - al margen de su limitada esfera de instrumentalización desde el supuesto fáctico interior a la norma-, su carácter innovador, la reserva del procedimiento abrogativo ${ }^{12}$, así como, ló-

5 Constantino Mortati: Le leggi provvedimento. Milán 1968, Giuffrè.

- A. A. Cervati, G. Grottanelli De Santi: La formazione delle leggi. Tomo I, 1 en Commentario della Costituzione a cura di G. BranCA, Art. 70-74, Bolonia 1985, Zanichelli, pág. 49. nota 28.

Ulrich K. Preuss, «Der Staat als Bewusst Produziertes Handlungzentrum». En E. W. Bockenforde (Hrg.) Staat und Gesellschaft. Darmstadt 1976. Wissenschafliche Buchgesellschaft, pág. 347.

\& V. M. MORISI: «Aspectos esenciales de la regulación económica en una constitución de la "crisis"», En A. Predieri, E. Garcia de Enterria, La Constitución Española de 1978. Civitas, págs. 363-409.

S C. MORTATI: "Contenuto e forma nella qualificazione o nel trattamento degli atti normativi", Rivista Trimestrale di Diritto Pubblico, 1970, págs. 15 y ss.

10 Mortati art. cit. y E. Chell: Potere regolamentare e struttura costituzionale. Milán 1967, Giuffrè.

11 En lo que insiste particularmente la doctrina y jurisprudencia alemana, V. Friedrich KLEIN, en MANGOLdT-KLEIN, artículo 19 Anm. III 1-2 y Stasrck, págs. 53 y ss.

12 V. MORTATI, art. cit. 
gicamente, su capacidad para operar limitaciones en la esfera de los derechos fundamentales.

Naturalmente este último contenido material es el que presenta una mayor importancia en el supuesto de la ley singular, en la medida en que introduce una colisión directa con el principio de igualdad. Hay, sin embargo, una relativa confusión de planos a la hora de entender las fricciones entre los postulados de igualdad y la limitación de derechos; reiterando una línea jurisprudencial ya conocida, el Tribunal Constitucional español recuerda en la citada Sentencia, cómo el artículo 14 CE «no prohibe al legislador contemplar la necesidad o la conveniencia de diferenciar situaciones distintas y darles un tratamiento diverso, porque la esencia de la igualdad consiste, no en proscribir diferenciaciones o singularizaciones, sino en evitar que éstas carezcan de justificación objetivamente razonable, enjuiciada en el marco de la proporcionalidad de medios al fin discernible de la norma diferenciadoran; un pronunciamiento muy próximo al que formula la Corte Costituzionale italiana en su Sentencia de 14 de abril 1969, núm. 80 , cuando establece que «il principio di eguaglianza richiede che la legge singulare corrisponda a una obbietiva diversitá della situazione considerata, rispetto a situazioni omogenee».

Sin embargo, el Fto. Jco. 11 de la STC citada perfila una confusa contraposición entre el carácter excepcional de toda norma singular, que colisiona con la vocación de generalidad que impone a las leyes «su propia estructura interna», frente al teórico carácter no excepcional de una hipótetica ley general que tuviera el específico objetivo de impedir el ejercicio de un derecho fundamental (apdo. c). Si en el primer caso la restricción del principio de igualdad impone unos requisitos adicionales de justificación objetivamente razonable ¿no habría de exigirse igualmente una idéntica razonabilidad y proporcionalidad en el caso de una ley general limitadora de derechos fundamentales?

Son dos, en efecto, los elementos diferenciables en este problema: la necesidad adicional de justificación objetiva de la norma singular como típica norma intervencionista, y la eventual y consecuente afectación del principio constitucional de igualdad ${ }^{13}$.

13 Hay, sin embargo, una mayor resistencia por parte de la doctrina alemana para aceptar limitaciones de derechos fundamentales por parte de leyes singulares (Einzelfallgesetzen). Asi Haman, Krûger, Scneider, Volkmars (cfr. STARcK cit. págs. 53-54); en cambio Klein (MANGOLDT-KLEIN, cit.) sitúa una alternativa entre leyes individuales o leyes singulares subjetivas (Einzelpersonengesetzen), frente a la ley singular objetiva o ley especial, que no estaria expresamente prohibida por ja Ley Fundamental, K. HUBER (Massnahmegesetz und Rechtsgesetz. Eine Studie zum rechtsstaatlichen Gesetzesbegriff. Berlín 1963, Dunker u. Humblot), aún aceptando las limitaciones del intervencionismo estatal coyuntural en la vida económica, insiste en el rechazo de la ley singular en la medida en que, por encima de sus condicionamientos causales objetivos, genera siempre consecuencias diferenciadoras subjetivas. En tales argumentos subyace siempre el carácter normativo de la garantía del principio de igualdad del artículo 3.1 de la Ley Fundamental. 
En el primer caso hemos pretendido sugerir el carácter relativamente arcaico del planteamiento que conduce a la falsa dicotomia ley general-ley singular, en el que subyace la contemplación de la ley general como la tópica regla de derecho o norma no intervencionista. Es éste fenómeno - la no intervención en la esfera de la sociedad- el auténtico soporte del paradigma normal de ley, cuando, como señala MORTATI ${ }^{14}$, la ley no está instrumentalmente conectada a las circunstancias o situaciones de hecho que la han ocasionado, y al no deber dar cuenta de su correspondencia con aquéllas, debe ser valorada $-y$ controlada - en términos de mera objetividad.

Sería pues la existencia o inexistencia de una vinculación instrumental de la norma con los supuestos fácticos que la predeterminan, exigiendo una respuesta activa de los poderes públicos, el elemento de diferenciación, y no el ámbito subjetivo que pretende normar ${ }^{15}$, por lo cual no existe necesariamente una correlación inmediata entre la estructura interna de la ley y el principio de igualdad-generalidad, pudiendo teóricamente existir normas intervencionistas, justificables como una respuesta a determinados condicionamientos fácticos de la realidad - y en consecuencia limitadas por los principios de razonabilidad y proporcionalidad-que, sin embargo, operan sobre una generalidad de destinatarios. Es una confusión que está igualmente presente en MORTATI al referirse ${ }^{16}$ al supuesto de que la ley persiga la finalidad de hacer frente a eventos que por su particularidad y excepcionalidad exigen derogaciones al derecho común, o en el caso de subrogación en la actividad prestadora de la administración, en tal caso no pueden dejar de hacerse valer particulares obligaciones a cargo del legislador, de dar cuenta de los motivos que han promovido la actividad normativa.

Habría pues una necesidad de justificación del soporte causal de la norma intervencionista, que legitime su adecuación a «casos excepcionales que por su extraordinaria trascendencia y complejidad, no son remediables por los instrumentos normales de que dispone la Administración» (STC cit. Fto. Jco. 11,B).

De este modo el derecho intervencionista del Estado adoptaría una configuración más realista de adecuación formal al marco causal, coyuntural y fragmentario, de las políticas de "crisis management" ${ }^{17}$, sin pre-

14 Art. cit., pág. 4.

is V. CH. STARCK, cit., pág. 55.

16 Art. cit., págs. 4 y ss.

17 Una hipótesis que en alguna medida constituiría una visión reactualizada de la opinión expresada por A. Predier (Pianificazione e costituzione. Milán 1963, ed. di Comunità) al defender la limitación de las leyes intervencionistas mediante su adecuación al programa económico global del Estado. Para Teubner existiria una diferenciación entre el «substantive law", basado en principios de justicia sustantiva, frente a un "reflexive law», cuya singularidad derivaria de its structure and its inner connection with problem-generating and problemen- 
tender fundamentarse en el único soporte legitimador de la iustitia distributiva, o en otras justificaciones generales de ordenación y conformación de la sociedad ${ }^{18}$.

'Sin embargo, este soporte instrumental de la ley singular intervencionista permitiria entender la ambigua hipótesis negativa sugerida por el TC, en relación con los derechos fundamentales, al referirse (Fto. Jco. 11,c) a la imposibilidad de leyes singulares «que tengan el específico objeto de condicionar o impedir su ejercicion (donde probablemente pueda ocultarse el eventual supuesto de una especie de «LOAPA de derechos fundamentales"); de lo que se deduciría que toda limitación generada en la esfera de los derechos fundamentales por una ley intervencionista sólo puede aceptarse como una consecuencia indirecta o derivada de la misma, que debe suponerse suficientemente compensada o justificada por la satisfacción del interés prioritario o directo que fundamenta su existencia. Sería aquí precisamente donde, en contra de PALADIN ${ }^{19}$, debe aceptarse la necesidad de una evidencia contextual fáctica que actúe como soporte causal de la norma, permitiéndose así, en el control final de la misma por el órgano competente, una ponderación de la razonabilidad y proporcionalidad entre el hecho causante, como soporte justificador de la acción normativa, y la limitación específica en la esfera de derechos fundamentales que la norma provoca; una limitación que en el supuesto de la ley singular tendría siempre un doble ámbito, el del derecho en cuestión afectado (la propiedad en el caso de la ley singular de expropiación ) y la del principio constitucional de igualdad.

4. Esta específica construcción de la norma intervencionista singular implicaría, pues, la integración simultánea de dos momentos operativos que en el esquema clásico de actuación del Estado de Derecho aparecen desdoblados, acto normativo habilitante y disposición intervencionista ${ }^{20}$, lo que va a condicionar profundamente el mecanismo de control de la norma.

garging organized social actors", v. art. cit. en nota (1), y también D. KETTER: «Legal Reconstitution of the Welfare State. A Latent Social Democracy Legacy", Law and Society, 1987, 1, págs. 36-37.

${ }_{18}$ No toda la doctrina apoya esta tesis de la motivación contextual de las leyes intervencionistas; en contra, PALADIN, en art. cit. Giur. Cos., 1969, págs. 887-88, se pronuncia en defensa del genérico valor de ley de cualquier norma intervencionista, añadiendo: "Nell'attuale sistema non risulta che le norme costituzionali impongano al legislatore ordinario nessun obbligo di motivazione»; aparte de que "la Corte Costituzionale ha sempre il modo di rivacare aliunde motivi sui quali si fondano le previsioni legislative, anche in mancanza di motivazioni contestuali». Para la visión del problema en la doctrina alemanà v. STARCK, cit., págs. 55 y ss. 19 Art. cit.

20 Una dualidad procesal que ha seguido defendiendo también alguna doctrina italiana en los años inmediatamente posteriores a la Constitución; asi Guarino, Esposito, Crisafulli, o Carlassare quien afirma que «per la limitazione dei diritti individuali e necessario il concorso 
En el sistema normal de fuentes del Derecho, el reforzamiento de las condiciones materiales de apoderamiento legal implica alternativamente la atribución de un marco de discrecionalidad u oportunidad al órgano ejecutivo, que es el encargado de estimar los presupuestos fácticos condicionantes de la eficacia del acto ejecutivo singular; tales elementos quedarian exentos de control en la medida en que éste se limitará a constatar las condiciones de validez habilitante. La evolución del intervencionismo estatal tiende a conducir a una exigencia, no siempre suficientemente respetada en la práctica, de progresiva concretización de los mecanismos de habilitación ${ }^{21}$, a través de la sustitución del apoderamiento global por apoderamientos especificados.

Sin embargo esta expansión de la política intervencionista sólo determina la necesaria puesta en práctica de garantías legales cuando se traduce en actos de gravamen o limitaciones de derechos, entendiéndose que los actos de favorecimiento están exentos de la reserva legal habilitante ${ }^{22}$, admitiéndose así que «la Administración conceda subvenciones $u$ otros actos de favorecimiento sin apoderamiento jurídico alguno» ${ }^{23}$; de donde podemos constatar la existencia de violaciones positivas del principio de igualdad al margen de toda reserva legal.

La determinación conceptual de la norma intervencionista singular implica, pues, un ámbito material consistente en la limitación justificada y directa de un derecho, que opera simultáneamente una violación negativa del principio de igualdad, concretándose en un mismo acto formal el momento habilitante y el acto directamente intervencionista.

Ello debería implicar una sustancial transformación del mecanismo de control que ahora no podrá limitarse ya a la mera constatación de los presupuestos de validez del acto, pues éste tiene rango de ley, debiendo proyectarse alternativamente sobre los condicionamientos materiales causales de la norma, en un intento de constatar la razonabilidad y proporcionalidad de la limitación singular instrumental de un derecho que, simultáneamente, implica una violación o restricción del principio de igualdad.

De esta forma las leyes que poseen una auténtica «sustancia de acto ejecutivo" implicarán una mayor actuación y penetración del control de constitucionalidad, con la asunción por parte del juez de una serie de poderes de indagación sobre el supuesto de hecho, que no se limitan a cons-

di una coppia di atti, l'uno legislativo e l'altro amministrativo»; Guarino, con referencia a los supuestos de expropiación, sigue defendiendo también la tradicional doctrina «il compito della legge e quello di prevedere o disciplinare le espropiazioni, ma non di procedere in concreto ad esse e di portarle a compimento od eseguirle», v. PALADIN art. cit., pág. 877, nota (17). EI propio Paladin se refiere así a una «riserva bipartita, entro la quale il momento normativo rimane affidato al legislatore, mentre il momento esecutivo ricade dell'esclusiva competenza dell'amministrazione o delle giurisdizione».

\footnotetext{
${ }^{21}$ D. JeSCH, op. cit., pág. 273.

22 lbidem, pág. 235.

23 Idem, pág. 232.
} 
tatar la específica competencia, debiendo entrar formalmente a comprobar si el hecho (fatfo) causante asume el carácter de acto que justifica razonablemente la producción de una norma con rango de ley.

Debe señalarse que esta expansión cuantitativa del mecanismo de control implica simultáneamente una sustancial transformación cualitativa del mismo en cuanto determina la superación del mero control sobre el marco condicional de la actuación estatal como soporte de su validez, para pasar a apreciar elementos finalistas y de adecuación de la norma a los objetivos, ajustados a los hechos, que la motivan; lo que, de pasada, implicaría ciertamente la negación al Poder Legislativo del habitual espacio de discrecionalidad, necesario para concretar la adecuación de medios a fines, reconocido tradicionalmente al Ejecutivo, como principal articulador de la capacidad transformadora de la realidad social, genéricamente atribuida a los poderes públicos en el marco del Estado Social intervencionista.

La interrogante consistirá entonces en determinar si es posible entender una función de control judicial, con posibilidades reales de éxito, que deba entrar a conocer y valorar el mismo núcleo político esencial de la función legislativa, es decir, la opción entre respuestas decisionales alternativas frente a un determinado tipo de valoración de hechos sociales, teniendo en cuenta las pretensiones finalistas o programáticas de los poderes públicos ${ }^{24}$.

5. En el supuesto de la ley expropiatoria singular es la causa expropiandi la que ufunciona como criterio de razonabilidad y proporcionalidad de la medida legislativa expropiatoria, de manera igual a como lo hace el fin discernible en las normas diferenciadoras dentro del principio de igualdad, al cual, indudablemente, vienen sometidas dichas medidas" (STC cit. Fto. Jco. 13, A).

La peculiaridad del procedimiento de control constitucional de la citada Ley Rumasa, a través del procedimiento incidental de la cuestión de inconstitucionalidad en el que el propio juez a quo desestimó la inconstitucionalidad denunciada por los interdictantes en relación con los artículos 33, 9 y $14 \mathrm{CE}$, ha impedido un pronunciamiento del supremo tribunal sobre el nexo causal de la ley singular citada, aunque acepta en su Fto. Jco. 15, a, la posibilidad teórica de una inconstitucionalidad «fundada en injustificada expropiación por ausencia de razonabilidad y proporcionalidad en la privación de aquellos bienes o derechos".

Ello dejaría abierto el problema subyacente de cuáles podrían ser los parámetros de constitucionalidad utilizables para, ante una declaración

${ }^{24}$ Interrogante que se reproduciría potencialmente siempre según Paladin, si aceptamos su hipóteșis, antes apuntada de que "la C.C. ha sempre il modo di ricavare aliunde i motivi sui quali si fondano le previsioni legislative, anche in mancanza di motivazioni contestuali». 
legislativa de utilidad pública e interés social, enjuiciar su razonabilidad o proporcionalidad respecto a una situación coyuntural de determinados elementos de la realidad económica, con capacidad para afectar los intereses generales del orden social, y la seguridad del sistema económico tutelables por el Estado.

A semejanza con el concepto de la extraordinaria y urgente necesidad, que legitima la actuación normativa del Ejecutivo por la vía del Decreto-Ley, el concepto de utilidad pública e interés social aparecería como una cláusula abierta y relativamente indeterminada, que abre el camino hacia un núcleo decisional de carácter político, de difícil ponderación a través de los mecanismos normales de la dogmática juridica. Para el juez ordinario, el requisito de la declaración de utilidad pública e interés social actúa en efecto como un soporte habilitante suficiente para aceptar la legalidad de la medida expropiatoria: sin embargo, para el juez constitucional se presentaría el desafío de aplicar parámetros extraconstitucionales para intentar apreciar, en el ámbito contextual socioeconómico, la adecuación razonable y proporcional de las medidas adoptadas al soporte causal específico de la norma, apareciendo la irremediable amenaza de un modelo singular de control, técnico-económico o político, como soporte de la constitucionalidad de una ley.

Por encima de estas dificultades operativas para la construcción de un modelo funcional de control de constitucionalidad del soporte causal de actuaciones legislativas intervencionistas singulares ${ }^{25}$, subyace el problema más general de la progresiva asunción por los poderes públicos de una función global activa de tutela de la "seguridad» económica del mercado: lo que implicará no solamente una articulación de instrumentos político-normativos que refuercen las premisas de "openness and accountability» ${ }^{26}$ del conjunto del sistema, operando una progresiva transformación en los tradicionales límites que separan lo público de lo privado -como hasta ahora ha venido insistiendo una reciente doctrina, básicamente anglosajona, a partir de una recepción implícita, en clave progresista, de hipótesis neoliberales que insisten en el evidente fenómeno de la socialización del Estado ${ }^{27}$-; por el contrario, la extensión del ámbito de tutela de la seguridad del mercado no se limita a la hasta ahora tradicional actuación prestadora a posteriori frente a las deseconomías sociales gene-

25 Donde obviamente no sería operativa la tradicional dogmática jurídica en el sentido de N. Lummann: Stato di diritto e sisteme sociale. Napolés 1978, Guida.

${ }_{26}$ V. Norman LEwIS: «De Legalisation in Britain in the 1980s", en P. MCAUSLAN, J. McEldowner, Law, legitimacy and the Constitution, cit.; también Ibid. T. Proser, cit. "Democratisation, Accountability and Institutional Design: Reflections on Public Law», págs. 170 y ss.

${ }^{27}$ V. G. Teubner, cit.; T. Proser, cit.; Nonet \& Selznick, cit.; v. también N. Lewis \& P. WILES: “The Post-Corporatist State?», J. of Law and Society, 1984, 11, págs. 65-90. 
radas por el sistema económico capitalista ${ }^{28}$; la «protection against market risks» ${ }^{29}$ implicaria simultáneamente un desarrollo de la genérica función estatal de seguridad, que ahora asumiria una progresiva capacidad de penetración sobre el entramado del sistema económico.

Una penetración que se presenta como un fenómeno de relegalización del sistema, y a la vez como una progresiva presencia funcional del Estado como tutelador del mismo: en palabras de David Kettler ua relegalized society that is increasingly dependent on punitive rather than on regulative laws ${ }^{30}$. De donde emergería, pues, la presencia de un eventual elemento inductor y legitimador del soporte causal de la ley intervencionista singular, la tutela de la seguridad del sistema, cuyo carácter esencialmente estatal (en el sentido suprapolítico) tiende a dificultar considerablemente la posibilidad de apreciación concreta, a partir del supuesto fáctico de la realidad económica afectada por la norma, de las premisas de razonabilidad y proporcionalidad que constituyen su soporte actual.

2a V. entre otros I. Gough: Econom/a politica del Estado de bienestar. Madrid, Blume, 1982. J. O'Connor: La crisis fiscal del Estado. Barcelona 1981. Carlos de CABo: La crisis del Estado Social. Barcelona; PPU, 1985.

20 V. K. AUSTIN: "The problem of Legitimacy in the Welfare State", Pennsylvania Law review, 1982, 130, pág. 1510.

so D. KeTtLen, art. cit. Law and Society, 1987. 